\title{
Conflicts and Compromise: Using of Chinese Standards in China-aided Stadium Projects After 2000
}

\author{
Wei Chang ${ }^{1,2,3, *}$, Charlie Qiuli Xue ${ }^{2,3}$, Yingting Chen ${ }^{2,3}$ \\ ${ }^{1}$ School of Civil Engineering, Tangshan University, Tangshan, China \\ ${ }^{2}$ Department of Architecture and Civil Engineering, City University of Hong Kong, Hong Kong, China \\ ${ }^{3}$ Shenzhen Research Institute, City University of Hong Kong, Shenzhen, China
}

Email address:

successc_w@163.com (Wei Chang)

${ }^{*}$ Corresponding author

\section{To cite this article:}

Wei Chang, Charlie Qiuli Xue, Yingting Chen. Conflicts and Compromise: Using of Chinese Standards in China-aided Stadium Projects After 2000. International Journal of Architecture, Arts and Applications. Vol. 6, No. 2, 2020, pp. 27-33. doi: 10.11648/j.ijaaa.20200602.13

Received: May 20, 2020; Accepted: June 22, 2020; Published: June 29, 2020

\begin{abstract}
Since the 1950s, China began to provide aid constructions to developing countries in Asia, Africa and Latin America. Among these constructions, stadium projects occupied a significant proportion, and produced great influence due to its high investment, large scale and obvious image. Since Chinese standards were required to be used in the design, management and construction process of China-aided stadiums, whether and how the Chinese standards can be well applied to various recipient regions becomes one of the key issues, which is worthy of the specific study. This is increasingly more significant in recent years, with the social and economic development of the recipient areas. Conflicts between the Chinese standards and the local ones may happen and compromises are required to solved the problem. Therefore, this study aims to explore the exportation of Chinese standards in China-aided stadium projects after 2000 based on interview studies. Statistical analysis and content analysis research methods are used in the analyzing of the interview contents. This study tries to explore the current situation, problems and solutions (countermeasures) when using Chinese standards in China-aided stadium projects after 2000. The applicability and practicability of Chinese standards are also evaluated, and the guidance and suggestions for future construction projects are summarized.
\end{abstract}

Keywords: China's Foreign Aid, China-aided Stadiums, Chinese Standard

\section{Introduction}

China's aid activities started in the 1950s as part of its commitment to the socialist, which were later exported to developing countries in Asia and Africa in order to gain friends among non-allied forces, including facilities for manufacturing, agriculture, sport, medicine and construction [1]. According to the Chinese government, by 2018, over 2,000 projects had been completed in more than 160 countries, and over 1,500 buildings had been constructed ${ }^{1}$. The growing number of China-aided projects has attracted increasing attention and study, since China became a main

1 This number was estimated by the authors through the number of aid projects announced by Chinese government and the real cases the authors have collected. provider among non-DAC ${ }^{2}$ countries [2-4]. Many studies have focused on the political aims behind these aid projects [5-10] or the relationship between the allocation and benefits that China subsequently might achieve in various regions [11-13].

In fact, in all of its overseas aided construction projects, as assigned by the central departments of the Chinese government, China has been responsible for the entire

2 DAC (Development Assistance Committee) is one of the most dominant aid organizations worldwide, which is from OECD (Organization for Economic Co-operation and Development), consists of 30 members including U.S., U.K., Japan, Korean and some European countries, and mainly provide Official Development Assistance (ODA). Countries outside DAC but also provide ODA to other areas are referred as non-DAC countries, such as China and India. 
process - from the initial planning stages to the completion, which is normally described as the "turn-key"3 model. It is one of the compulsory requests to use Chinese standards in the design, management and construction processes. Since the 21 st century, China has increasingly promoted the oversea aid constructions with its standard going global. At the same time, foreign aid projects are faced with higher standards and more diversified requirement under the new situation. It consequently provides more opportunities as well as more challenges to the exportation of stadium projects abroad. After 2000, the market system was finally introduced into China-aided construction projects, and the companies that designed and managed these projects were selected through special bid operation ${ }^{4}$. But using Chinese standards was maintained to be compulsory requirement for most Chinese aid construction projects.

To conduct our research about Chinese standards in China-aided construction projects in the new era, we chose to study stadiums first. One of the main reasons to start with stadium is that they are one of the most prominent and major types of aided construction projects. To date, over 100 China-aided stadiums have been financed, designed and constructed in various regions $[14]^{5}$. Compared with other China-aided construction projects ${ }^{6}$, stadiums are among the most famous and longest lasting ones, and they usually have a comparatively large scale and level of investment, a complicated structure, an obvious image in the context, and a multicultural background and discourse surrounds them. Most of these stadiums were donated for preparing significant international sports events, and the commitment by the Chinese government was made at the request of the recipient countries. Additionally, as stadiums play significant roles in representing the local area's image and in improving the quality of local infrastructure, and stands as the symbol of the nation, some of the recipient countries would like to involve more in the design and management process, which may lead to some conflicts for using Chinese standards. Due to such special attributes of China-aided stadiums, how Chinese standards work on these projects tend to be more obvious and revealing. After 2000, the architectural characteristics of China-aided stadiums transformed from designs with socialist ideas into designs with regionalist and international ideas $[15,16]$, reflecting the change in operation patterns in the design and management of the projects. Meanwhile, the fast-growing number of China-aided stadiums since the turn of the century has tripled from the numbers in the previous 40 years, and many of the projects have become known worldwide for their high standards, high cost and vast influence. Under

\footnotetext{
3 This term was used officially to describe the model in which China completed all the design, management and construction parts then handed the project over to the recipient country.

4 The specialties of bid operation within these aided construction projects will be explained in later paragraphs.

5 Calculated by the authors.

6 Other constructions include schools, hospitals, housing projects, office buildings and cultural buildings, etc.
}

such circumstances, how did the conflicts be solved and what or whether compromises existed would be interesting and useful to investigate.

\section{Method}

Although the investment amounts, basic information and regulations regarding China-aided construction projects can be found on the official website of the Chinese government, there is little mention of the situation of using Chinese standard. Most China-aided stadium projects were unreported beyond a limited and superficial introduction, except for star projects that were visited by key Chinese political leaders ${ }^{7}$. Due to the difficulties in interviewing members of government departments, we are only able to examine the real stories by interviewing the designers, managers or other professionals involved. Therefore, we chose to develop this research through interviews among experienced practitioners in China-aided stadium projects. As the leader of most official aid projects, the Department of Foreign Assistance ${ }^{8}$ in the Ministry of Commerce of the People's Republic of China (MOFCOM) has awarded the design and management of overseas aid projects every few years (approximately three years) to certain groups of qualified state-owned enterprises. The list of such qualified enterprises was once not public record, but in 2016, MOFCOM posted the "Guanyu bufen leibie yuanwai xiangmu shishi qiye zige zhaobiao zhongbiao danwei mingdan (List of qualified enterprises that won bids to implement certain categories of foreign aid projects)" online 9 . Twenty institutions were listed as ones that were qualified to design and manage civil aided construction and industrial aided construction projects. These 20 institutions have been the main participants in the design and management of China-aided construction projects over the past 60 years. Only the companies on this list are authorized to submit bids for the design and management of China-aided construction.

We chose to interview 28 participants from 10 of those that have frequently been involved in China-aided stadium projects. Through the statistical and content analysis of the interviews, we aimed to find the current situation of using Chinese standards in China-aided stadium projects. Based on grounded theory [17-19], we planned to explore the interviews, verify and compare them with the research findings, and finally present our conclusions.

\footnotetext{
7 For example, in July 22nd, Chinese president Jinping $\mathrm{Xi}$ attended the project-hand-over ceremony of China-aid Wrestling Stadium in Senegal during his state visits to Africa, which was reported by various domestic and worldwide media.

8 In 2018, this department has been regrouped as the China International Development Cooperation Agency.

9 This list was announced in the official website of MOFCOM. http://yws.mofcom.gov.cn/article/o/i/201601/20160101234363.shtml.
} 


\section{Participants and Questions}

The 10 institutions that we conducted the interviews include Beijing Institution of Architectural Design (BIAD), China Architecture Design \& Research Group (CADRG), China IPPR International Engineering Co., LTD (IPPR), SIPPR Engineering Group (SIPPR), Shanghai Xian Dai Architectural Design (Group) (SXDADG), Shanghai Institute of Architectural Design \& Research Co., LTD (SIADR), China Sports Industry Group (CSIG), Central South Architectural Design Institute (CSADI), China Urban Construction Design \& Research Institute (CUCDRI), and Radio Film \& Television Design \& Research Institute (RFTDRI). As Liamputtong and Ezzy (2005) pointed out, A careful selection of information-rich participants can provide a thorough and sophisticated understanding of a subject matter from all dimensions. In our research, the criteria used for the sampling include the participants' willingness in participate the research, their different knowledge bases and experiences in aided stadium projects, and their roles in their respective institutions. Therefore, we aimed to interview participants with various years of experience involved in aid projects, who held different professions and positions in various procedures within the implementation of the aided stadium projects. This enabled us to have a relatively comprehensive and concrete understanding of the issue.

A total of 28 participants from the 10 target institutions were chosen for interviews. Face-to-face interviews were conducted between January 2018 and January 2019; the participants included architects (AD, architectural designer) (13), engineers of other professions (ED, engineering designer) (5), and managers (MG, manager) (10) (Table 1).

Table 1. Information about interview participants.

\begin{tabular}{|c|c|c|c|c|}
\hline Participant No. & Profession & Role/position & Years of experience in aid project & Institution \\
\hline 1 & architecture & MG & $5-10$ & BIAD \\
\hline 2 & architecture & $\mathrm{AD} / \mathrm{MG}$ & $5-10$ & BIAD \\
\hline 4 & architecture & $\mathrm{AD}$ & 5 & BIAD \\
\hline 5 & civil engineering & ED & $45-40$ & CADRG \\
\hline 6 & architecture & $\mathrm{MG} / \mathrm{AD}$ & $10-15$ & CADRG \\
\hline 7 & architecture & $\mathrm{AD} / \mathrm{MG}$ & $20-25$ & CADRG \\
\hline 8 & architecture/civil engineering & $\mathrm{AD} / \mathrm{ED}$ & $35-40$ & IPPR \\
\hline 9 & architecture & MG & $20-25$ & IPPR \\
\hline 10 & architecture & $\mathrm{AD}$ & 5 & IPPR \\
\hline 11 & architecture & $\mathrm{AD}$ & 5 & IPPR \\
\hline 12 & civil engineering & MG & $15-20$ & SIPPR \\
\hline 13 & economics & MG & 5 & SIPPR \\
\hline 15 & architecture & $\mathrm{AD}$ & $15-20$ & SIPPR \\
\hline 16 & urban planning & $\mathrm{AD}$ & $5-10$ & SIPPR \\
\hline 17 & architecture & $\mathrm{AD}$ & $1-5$ & SIPPR \\
\hline 18 & architecture/civil engineering & $\mathrm{MG} / \mathrm{ED}$ & $25-30$ & CSIG \\
\hline 19 & architecture & $\mathrm{AD}$ & $5-10$ & CUCDRI \\
\hline 20 & architecture & MG & 5 & CUCDRI \\
\hline 21 & architecture & $\mathrm{AD}$ & $15-20$ & RFTDRI \\
\hline 22 & ventilation & MG & $15-20$ & RFTDRI \\
\hline 23 & architecture & $\mathrm{AD}$ & $10-15$ & CSADI \\
\hline 24 & architecture & $\mathrm{AD} / \mathrm{MG}$ & $10-15$ & CSADI \\
\hline 25 & architecture & $\mathrm{AD} / \mathrm{MG}$ & $30-35$ & SXDADG \\
\hline 26 & architecture & $\mathrm{AD} / \mathrm{MG}$ & $10-15$ & SXDADG \\
\hline 27 & architecture & $\mathrm{AD} / \mathrm{MG}$ & $35-40$ & SXDADG \\
\hline
\end{tabular}

To achieve more objective perspectives and facts about stadium projects after 2000, the interview questions were designated before the interview. Each participant was given a paper with 9 basic questions ${ }^{10}$ (Table 2). These questions could simply be answered yes or no, but the interviewers were

10 In most circumstances, the hope was that participants would answer all 9 questions. However, there were some situations in which the participants chose to answer only some of the questions due to time, privacy, classified information or a lack of willingness to answer. encouraged to be flexible and aimed to guide participants to discuss more about certain questions or topics. The order of the questions was arranged to encourage the participants to answer more fully. Most participants were willing to talk more in depth about the same types of topics. All interviews were tape-recorded, accompanied by notes, and transcribed immediately afterward ${ }^{11}$.

11 In total, we collected over 50,000 words of interview contents. 
Table 2. Interview question list.

\begin{tabular}{ll}
\hline No. & Question \\
\hline 1 & Did the China-aided stadium projects use Chinese standards? \\
2 & Did the China-aided stadium projects use materials from China? \\
3 & In your opinion, is it positive to use Chinese standards in China-aided stadium projects? \\
4 & Were there any problems/conflicts when using Chinese standards in China-aided stadium projects? \\
5 & Were the problems/conflicts solvable? \\
6 & Did the China-aided stadium projects cost higher than China's normal domestic stadium projects? \\
7 & Did the China-aided stadium projects take longer time to complete than China's normal domestic stadium projects? \\
8 & Did the recipient country accept to use Chinese standards? \\
9 & Was the recipient country satisfied with the stadium projects with Chinese standards? \\
\hline
\end{tabular}

\section{Statistical Analysis of the Yes/No Answers}

First, we calculated number of different answers to each question, as listed below (Figure 1), and we analysed the results.

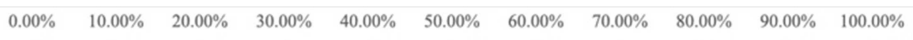

Did the China-aided stadium projects use Chinese standards?

Did the China-aided stadium projects use materials from China?

In your opinion, is it positive to use Chinese standards in China-aided stadium projects?

Were there any problems/conflicts when using Chinese standards in China-aided stadium projects?

Were the problems/conflicts solvable?

Did the China-aided stadium projects cost higher than China's normal domestic stadium projects?

Did the China-aided stadium projects take longer time to complete than China's normal domestic stadium projects?

Did the recipient country accept to use Chinese standards?

Was the recipient country satisfied with the stadium projects with Chinese standards?
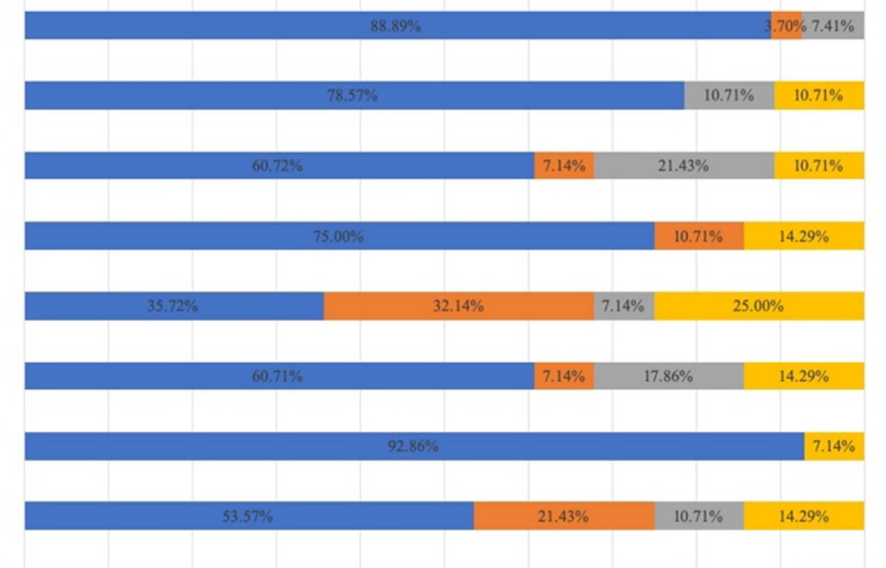

mes $\quad$ no $\quad$ neutral $\|$ no answering

Figure 1. Percentage of different answers to interview questions (Drawn by the authors).

"Did the China-aided stadium projects use Chinese standards?", most participants gave similar percentages of affirmative answers (25 "yes", 88.89\%). This means that for all of the China-aided stadium projects, they used Chinese standards. "Did the China-aided stadium projects use materials from China?", 22 participants indicated the fact that most of the China-aided stadium projects used materials from China. It also explains the higher cost and longer time of these stadium projects compared to the costs of domestic ones (question 6, "Did the China-aided stadium projects cost higher than China's normal domestic stadium projects?", 17 "yes", 60.71\%; question 7, "Did the China-aided stadium projects take longer time to complete than China's normal domestic stadium projects?", 26 “yes", 92.86\%); it was due to overseas construction and materials transportation. Although the major proportion of participation hold positive views towards using Chinese standards in China-aided stadium project, they also admitted that problems/conflicts happened due to the using (question 3, "Did the China-aided stadium projects take longer time to complete than China's normal domestic stadium projects?", 17 “yes", 60.72\%; question 4, "Were there any problems/conflicts when using Chinese standards in China-aided stadium projects?", 21 "yes", 75\%). Some of these conflicts could be solved, while others could not, or not easily could (question 5, "Were the problems/conflicts solvable?", 10 "yes", 35.72\%, 9 "no", $32.14 \%$, 2 "neutral", 7.41\%), which means that the resolutions may be complex. For the half of the circumstances, the recipient countries accepted to use Chinese standards (question 8, "Did the recipient country accept to use Chinese standards?", 15 "yes", 53.57\%), while in others times it may need discussion or negotiation to achieve the agreement. Most of the recipient countries satisfied with the stadiums aided by China (question 9, "Was the recipient country satisfied with the stadium projects with Chinese standards?", 22 “yes", 78.57\%).

These results provide us with a general understanding of the situation of aided stadium projects from China. Through specific content analysis of the interview records, more perspectives and facts can be revealed, as explained in later 
sections.

\section{Content Analysis of the Interview Records: Perspectives and Facts from People's Narration}

In addition to directly answering yes or no to these questions, discussions around similar topics took up much more of the interview time. The qualitative data from the contents of the interview were then managed, coded and analyzed through the "content analysis" of the interview transcripts to reveal a wide range of perspectives from the participants and facts behind the stadium projects. The procedure for the analysis involved the following steps:

(1) Recoding all of the interview transcripts to obtain a preliminary sense of the range of concepts and terms (keywords) extracted from the expanded content;

(2) Repeating the previous step to identify and establish categories of concepts and terms and their underlying meanings;

(3) Conducting a search to determine the frequency of concepts or terms from the interview transcripts that matched the established categories;

(4) Transforming the categories of terms or concepts into numerical values and drawing conclusions from them.

Through such a procedure, the concepts and terms identified in the interview transcripts included the following:

(1) Compulsive Requirement, which includes concepts and terms that state the compulsory of using Chinese standards;

(2) Convenience/benefit, which involves concepts and terms that mention about the positive effects of using Chinese standards;

(3) Problem/conflicts, which encompasses concepts and terms related to the difficulty or challenge faced when conducting the project and the reasons behind the issues;

(4) Local adaptability, which includes concepts and terms that describe about how participants solve the conflicts through attentions on local adaptabilities.

As shown in the appendix, the "problem/conflicts" and "Local adaptability" categories were the most frequently mentioned, followed by the "convenience/benefit" and "compulsive requirement" categories. Here, we propose the three or two most frequent terms in each of the categories and show several examples from the interview transcripts; the keywords have black striking (Table 3).

Table 3. Top terms (keywords) and frequency of each category with examples from the content analysis of the interview transcripts.

\begin{tabular}{ll}
\hline & Compulsive Requirement \\
\hline Ex. 1 & We are required to use Chinese building codes in designing the stadium projects. After all, it is China who financed the project. (Participant 18) \\
Ex. 2 & We actually had an agreement when signing the contract that we should use Chinese standards in the stadium project. (Participant 7) \\
Ex. 3 & ...Therefore, we insisted on using our own standard...it is our project, so use our own standards and materials. (Participant 5) \\
\hline
\end{tabular}

\section{Convenience/Benefit. 19}

$\begin{array}{ll}\text { Ex. } 1 & \begin{array}{l}\text { It is much easier and more convenient for Chinese architects to design these oversea stadium projects to use Chinese standards. We do not have } \\ \text { spare time and energy to learn different standards when design for different regions. (Participant 3) }\end{array} \\ \text { Ex. } 2 & \begin{array}{l}\text { It is understandable to use Chinese standards. We donate the money, the materials and designs. If not, we cannot work efficiently (Participant 19) } \\ \text { Ex. } 3\end{array} \\ \text { For those undeveloped areas, they don't have any standards. Our standard is much better. We can provide better stadiums using Chinese standard } \\ \text { (Participant 6) }\end{array}$

\begin{tabular}{|c|c|}
\hline & Problem/conflict 25 \\
\hline Ex. 1 & When we chose to use some Chinese practices, they were slightly against the local climate. (Participant 15) \\
\hline Ex. 2 & $\begin{array}{l}\text { In terms of fire safety standards, they use the U.S.' [standards]. (designed with the Chinese building codes) It generated inconvenience for the } \\
\text { stadium }{ }^{12} \text { after construction, due to the fact that the local fire hydrant interface was not able to connect with those inside the stadium that follow } \\
\text { Chinese standards. I heard from one of the persons in charge that once in the opening of a large sport events with fireworks, there was a small fire } \\
\text { accident that happened in one of the areas, which caused a panic. (Participant 13) }\end{array}$ \\
\hline Ex. 3 & $\begin{array}{l}\text { Since the stadium }{ }^{13} \text { was using Chinese standards, the fire safety standard was not adapted to the local one, which uses American standards. The } \\
\text { local fire department could not give the stadium a passing grade on the inspection due to their regulations, although it has never stopped operating. } \\
\text { (Participant } 24 \text { ) }\end{array}$ \\
\hline & Local Adaptability \\
\hline Ex. 1 & $\begin{array}{l}\text { This project needs to adapt to relevant foreign building standards. If the local building codes are American, then we need to study the U.S. building } \\
\text { codes and its differences from China's. (Participant 28) }\end{array}$ \\
\hline Ex. 2 & $\begin{array}{l}\text { Indeed, we will try our best to consider local circumstances, including local common practices and materials...try to use local stuff, including local } \\
\text { elements, when using China's building codes. (Participant 17) }\end{array}$ \\
\hline Ex. 3 & $\begin{array}{l}\text {...we referred to some other key points, such as their building codes. If there are mandatory requirements on some aspects, we can also refer to } \\
\text { those. By contrast, if our specification is better than theirs, then we use ours, if not, we are likely to favour their control points. (Participant } 5 \text { ) }\end{array}$ \\
\hline
\end{tabular}

12 This stadium is the new national stadium in Costa Rica aided by China.

13 This stadium is the new national stadium in Costa Rica aided by China 
When asked about Chinese standards, participants discussed at length the use of Chinese standards, as has been required by the MOFCOM for a long time. Almost all participants agreed on their knowledge of and requirement to use Chinese standards. They mentioned that such a requirement was formulated probably for the convenience of Chinese technicians' customs and efficiency at work as well as to better control the project, and more easily export of Chinese products and labourers. Another reason was that many of the recipient countries did not have specific building standards or regulations because of their low-development status. Indeed, using Chinese standards allows the most comprehensive and obvious control over the design and management process for China-aided stadiums.

Specifically, one of the most frequent terms is the "local adaptability". Participants explained how they tried to adapt Chinese standards to local circumstances, including the local standards or building codes (if there were any). Some participants talked about how they had communicated with local authorities or representatives about their preferences. Some mentioned that they had compared the two sets of standards, circled the key-technical differences, and adjusted their designs according to the recipient country's customs, requirements, and practices. These adaptive behaviours were partly due to the "Eight Guiding Principles of Design ${ }^{14}$ ", as the first principle is "standards adaptability", and partly due to the reform of the management of overseas aided construction projects because the tender and bid system is involved: most participants stated that both Chinese experts and the recipient country's representatives tend to favour designs with more local adaptabilities.

For some less developed areas, the application of Chinese standards worked out well because those areas barely had formal standards of their own. However, for some post-colonial countries, who continue to obey the standards of their former suzerain even after independence, the insistence on using Chinese standards resulted in some problems, as explained in comments in the "problem" category. Such conflicts have been more serious in the recent years, as China began expanding its international aid to wider areas, including some middle-income countries included. For instance, as architect $\mathrm{Li}$ Fang (participant 28) from CSADI explained, in the design and management process of the new China-aided national stadium in Costa Rica that used Chinese standards, problems happened because of the differences in the safety standards of the two countries. Chinese technicians negotiated and adjusted the design several times to solve similar conflicts.

\section{Conclusion}

In conclusion, for China-aided stadium projects, it has been

14 "Eight Guiding Principles of Design" is the principles formulated by MOFCOM, which includes "standard application, overall planning, investment matching, function priority, technological innovation, environmental protection, convenient maintenance, sustainable development". compulsory requirement to use Chinese standards for ages, as Chinese standards have been more decisive in implementing these aided stadium projects. This inevitably shapes the outcomes, but also generate problems and conflicts. Chinese technicians need to solve these difficulties by adding local adaptabilities into these stadium projects through multiple methods.

In fact, using the donor's standard is a common principle in aid activities - not only in China's aid projects but also in those from other countries such as Japan, the U.S. and various European countries. Consequently, the architectural designs of some China-aided stadiums have a good design quality that considers the regional, cultural and local contexts, with combination of international style and cultural (national) -symbol elements, which is a significant part of modern Chinese architecture (Chang and Xue, 2019). From this view, the use of Chinese standards may not always be negative in certain aspects.

Generally, our research hopes to provide references and guidance for future aided construction projects and hopefully helps give a better understanding of China-aided systems at present. It is worth mentioning that the system is still constantly changing. According to some of the participants, MOFCOM is experimenting to use the localization mode (recipient-oriented) as a replacement of the "turn-key" (donor-oriented) mode. Whether and how Chinese standards will be utilized in the future and how that activity will manifest in the implementation of aid construction projects are questions that both deserve continual attention.

\section{Acknowledgements}

This paper was part of a study supported by the National Natural Science Foundation of China (NSFC), No. 51878584; Science and Technology Research Project of Colleges and Universities in Hebei Province, No. Z2019003; City University of Hong Kong, Project No. 7004966, No. 7005135.

\section{References}

[1] People's Republic of China State Council Information Office. (2011). White paper of China's foreign aid.

[2] Neumayer, E. (2003). Do human rights matter in bilateral aid allocation? A quantitative analysis of 21 donor countries. Social Science Quarterly, 84 (3), 650-666.

[3] Dreher, A., Nunnenkamp, P., and Thiele, R. (2011). Are "new" donors different? Comparing the allocation of bilateral aid between non-DAC and DAC donor countries. World Development, 39 (11), 1950-68.

[4] Fuchs, A. (2014). Determinants of Donor Generosity: A Survey of the Aid Budget Literature. World Development, 56, 172.

[5] Copper, J. F. (1979). China's Foreign Aid in 1978. School of Law, University of Maryland.

[6] Brautigam, D. (2011) China in Africa: Seven Myths. The Elcano Royal Institute/Real Instituto Elcano, Analysis of the Real Elcano Institute (ARI) 23/2011, Madrid, Spain, January 8. 
[7] Will, R. (2012). China's stadium diplomacy. World Policy Journal, 29 (2), 36-43.

[8] Siamphukdee, C. (2014). Introduction: "export architecture" and the cold war. Journal of Export Architecture: A War of the Worlds - Cold War Projects abroad. Deakin University, Deakin, pp. 1-2.

[9] Menary, S. (2015). China's programme of stadium diplomacy. ICSS Journal, 3 (3): 2-9.

[10] Dong, Y. \& Fan, C. (2017). The effects of China's aid and trade on its ODI in African countries. Emerging Markets Review, 33, $1-18$.

[11] Naím, M. (2007). Missing Links: Rogue Aid. Foreign Policy, $159,96-95$

[12] Noragric, P. W. (2011). China and Africa - Aid and development. EDS 270 Development Aid \& Politics.

[13] Kilama, E. (2016). The influence of China and emerging donors aid allocation: A recipient perspective. China Economic Review, 38, 76-91.

[14] Chang, W. and Xue, C. (2018). A Brief Introduction to the Regional Design Attempt of China-aid Sports Buildings. Architecture \& Culture, 175 (10), 241-243.

[15] Chang, W. and Xue, C. (2019). Towards International China-aid Stadiums in the Developing World. Frontiers of Architectural Research.

[16] Chang, W. and Xue, C. (2020) Climate, Standard and Symbolization: Critical Regional Approaches in Designs of China-aided Stadiums. Journal of Asian Architecture and Building Engineering. published online: https://www.tandfonline.com/doi/full/10.1080/13467581.2020 .1749060 .

[17] Glaser, B., and Strauss, A. (1967). The discovery of grounded theory: Strategies for qualitative research. New York: Aldine de Gruyter.

[18] Patton, M. Q. (1990). Qualitative evaluation and research methods. Newbury Park, CA: Sage.
[19] Strauss, A. and Corbin, J. (1998). Basics of qualitative research: Techniques and procedures for developing grounded theory (3nd ed.). Thousand Oaks, CA: Sage.

\section{Biography}

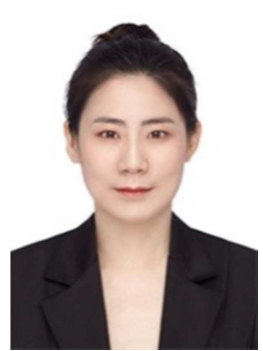

Wei Chang $\mathrm{A} \mathrm{PhD}$ candidate at the City University of Hong Kong and is researching about China-aided construction projects in the developing world. She works as a lecturer in Tangshan University of China. She has published numbers of papers about China's foreign-aided stadiums and constructions.

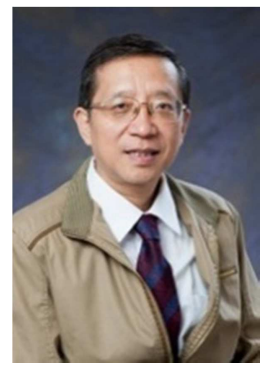

Charlie Qiuli Xue Associated professor of the City University of Hong Kong. An author of 10 books and hundreds of academic articles published in China and abroad, Xue' research focuses on the topics of architectural design globalization, post-war Hong Kong architecture, high-density architectural design and China's foreign-aided constructions.

Yingting Chen $\mathrm{A} \mathrm{PhD}$ candidate at the City University of Hong Kong, with 5-year practice experience in the context of urban design, landscape architecture and architecture. Research interest lies on human-nature relationship, impact of design on health and wellbeing, and international design exchange and cooperation. Current research focuses on China's foreign-aided construction projects. 